\title{
A prática com a pulsão: do esquecimento à redescoberta
}

\section{Practice with the drive: from oblivion to rediscovery}

Com uma escrita ao mesmo tempo clara e complexa, didática e poética, e um pensamento rigoroso e inovador, ao mesmo tempo aberto e sistemático, usando de maneira desimpedida os dizeres de psicanalistas, filósofos, artistas e analisantes, João Perci Schiavon busca refundar a psicanálise a partir da pulsão. ${ }^{1}$ Esta tem sido tratada como um conceito meramente teórico, "mitologia científica", e não como a própria pulsão enquanto noção exige: como prática clínica e uma questão de vida e morte. E como seria diferente pois, como Lacan (1979) disse, cada psicanalista não tem de reinventar, com sua prática,

*1 Universidade Federal do Maranhão - UFMA (São Luis, MA, Brasil).

${ }^{1}$ Perci já havia ensaiado essa reconstrução em dois livros anteriores (Schiavon, 2002, 2003) e resumiu esse esforço em um artigo (Schiavon, 2018). 


\section{RESENHAS BIBLIOGRÁFICAS}

a psicanálise? E é justamente sobre prática, e, por conseguinte, avaliação constante do agir, e, mais ainda, sobre uma ciência da ação, uma ética chamada psicanálise, que deseja produzir a diferença absoluta e exige a invenção, que versa o livro que ora resenhamos.

Os psicanalistas perderam o rumo porque desconhecem a orientação imanente da sua clínica, oriunda da pulsão. De tanto se fiarem a um pensamento da representação, analisando os ditos do inconsciente, suas formações, sua lógica, as imagens e suas identificações, acabaram por se perder do filão próprio à análise, ou seja, do phylum vital que reúne esses inúmeros ditos e sua consistência ética: esqueceram-se da pulsão e seu dizer além da representação, um dizer que ex-siste a todo dito (Lacan, 1972-73/1982). Influenciado por Hegel e Lévi-Strauss em uma lógica da falta, da negatividade e da estrutura, Lacan viu as intensidades pulsionais como o negativo da lógica do inconsciente. Schiavon, por sua vez influenciado por Nietzsche e Deleuze, no primeiro capítulo "Uma vida, um dizer", evidencia que, desde Freud, e em cada ato do inconsciente que se autoriza por si, como os lapsos, sonhos, sintomas e nas produções artísticas, a pulsão é um dizer, uma vida desconhecida, uma avaliação em ato e uma afirmação primordial, originária.

A pulsão, como força constante e exigência de trabalho, tem por destino originário a sublimação, formação do inconsciente que não passa pelo recalque: eis o segundo esquecimento dos psicanalistas. Em virtude disso, concebeu-se a pulsão como uma força entre o físico e o psíquico; vivas e intensas, porém, acéfalas. Ora, Schiavon nos mostra que justamente porque a pulsão é por princípio uma entidade de fronteira, que atravessa os planos, é também lúcida e avaliativa, inteligente e intuitiva, um pensamento sempre interessado.

No segundo capítulo, "O sentir, o saber e o sentido", o real é apresentado como ação que visa a satisfação, gozo do saber (jouissance): um saber de não senso, que não reconhece nenhuma instância fora de si para se autorizar, pois se orienta de maneira singular. $\mathrm{O}$ inconsciente real, pulsional, vivo (ainda que não orgânico), não reconhece a negação por ser uma afirmação primordial e reúne, por conseguinte, todo o paradoxo, que trama secretamente a vida atemporal do inconsciente. Essa orientação pragmática diz respeito a uma vida singular e impessoal - pois não possui modelo, mas inventa o seu modo de ser pelos seus atos, que implicam escolhas e decisões. O que importa para um é diferente para outro, e esse saber singular e prático que o manejo clínico com a pulsão confere à psicanálise, é, como pensou Lacan, um saber de não senso. Mas esse não sentido é apenas aparente: nasce das perspectivas antigas, superadas, da 
estrutura do Outro e das identificações do eu que as sustentavam, eu que perde sua soberania para se subordinar ao sujeito real do inconsciente, a pulsão.

O real é um furo da estrutura e a desterritorialização sublimatória das estruturas clínicas, que respondem ao recalque. A pulsão e seu sentido singular não pertence a esse mundo, ainda que seus efeitos sejam sentidos por esse e seja mesmo a fonte de tudo que chamamos de cultura, arte, ciência, filosofia e todos os dizeres. O real em psicanálise é o impossível, pois não pertence à ordem dos possíveis, a ordem desse mundo (simbólico-imaginário); é estrangeira, alienígena, do Fora. Contudo, como o real não é uma falta de representação, mas o que a produz, enquanto prática ele se cria e, em seu desejo, recria a realidade psíquica e social. É por isso que o real deixa de ser um problema ontológico (a naturalização do gozo de certa vertente lacaniana atual) para se tornar um problema ético, mas também estético, ou seja, sempre clínico - e com consequências políticas (Schiavon, 2020).

No terceiro capítulo, "As forças pulsionais", não abrir mão de seu desejo é apresentado como saber escutar (ob-audire, obedecer) o saber de não senso. É a partir dele, que não serve a nenhum bem, que se medem e avaliam todos os bens. Nessa prática com a pulsão como impulso lúcido, de uma lucidez 478 superior e vital, além do princípio do prazer e além do homem (porque é além do eu), só os graus superiores, a própria superação, importam. Ou seja, a vida busca originariamente não a morte, mas uma outra vida. Mesmo a pulsão de morte torna-se uma prática, uma ausência de exercício pulsional, de decisão e ação pela vida, ou uma confusão das linhas vitais com o meio derivado e dos significantes do Outro que mortificam o corpo. Por isso a pulsão de morte é como a micropolítica do fascismo: impulso e linha de destruição e autodestruição.

Tal como é mostrado no capítulo quatro, "O tempo da pulsão", a pulsão de vida, a única originária, se orienta por um mais ainda, por um gozo do saber que sobrevoa diversos estratos arqueológicos, ordenando-os segundo uma hierarquia de potência, uma composição afetiva e intelectual. A temporalização pulsional se ordena segundo perspectivas vitais de discernimento, do que vem antes e depois, do que quero fazer e como fazer: um saber-fazer inconsciente que se torna íntegro ou cristalizado na ação. Pois o real ou a pulsão é como o corpo sem órgãos de Deleuze e Guattari (2013): é um dado, mas tem de ser construído. Esse saber intempestivo só existe se exercido, se praticado, ou seja, se autorizando.

É nesse sentido que a pulsão enquanto exercício constante de sublime-ação é um gozo do saber, satisfação como um saber-fazer, como na arte, 


\section{RESENHAS BIBLIOGRÁFICAS}

onde cada obra de um artista, ou um dito, jamais esgota o seu dizer, sua própria subjetividade artística em devir e criação (Schiavon \& Pelbart, 2020). Tal como é mostrado no último capítulo "O saber da cura", essa subjetividade pulsional é capaz, no processo de sua (auto)produção, de avaliar seu percurso, a partir de sua condição de escolha sempre aberta, sua indeterminação — que, vista por si, é uma hiperdeterminação, uma constância que confere a uma obra e uma vida seu afeto e sua ideia, integridade ética em que sua verdade pode se dizer inteira a cada vez. Cura é o nome que se dá a esse exercício.

\section{Referências}

Deleuze, G., \& Guattari, F. (2013). Como criar para si um Corpo sem Órgãos? In Mil Platôs: capitalismo e esquizofrenia 2. (2. ed.; pp. 11-34). São Paulo, SP: Ed. 34.

Lacan, J. (1979). Conferência de 9 de julho de 1978. Lettres de l'École, 25(II), 219-220 .

Lacan, J. (1982). O seminário. Livro 20: mais, ainda. Rio de Janeiro, RJ: Zahar. (Trabalho original publicado em 1972-73).

Schiavon, J.P. (2002). O caminho do campo analítico. Curitiba, PR: Travessa dos editores.

Schiavon, J.P. (2003). A lógica da vida desejante. Curitiba, PR: Criar Edições.

Schiavon, J.P. (2018, jan-abr.). A imanência analítica. Ágora, XXI(1), 116-126.

Schiavon, J.P. (2020). Nossa humanidade. Pandemia crítica. Recuperado em 11 jan. 2021 de: <https://www.n-1edicoes.org/textos/126>.

Schiavon, J. P., \& Pelbart, P.P. (2020, set-dez.). Subjetividade literária. Ágora, XXIII(3), 38-46.

Citação/Citation: Costa, M. J. de A. (2021, jul.). A prática com a pulsão: do esquecimento à redescoberta. Resenha do livro Pragmatismo pulsional: clínica psicanalítica. Revista Latinoamericana de Psicopatologia Fundamental, 24(2), 476-480. http://dx.doi.org/10.1590/ 1415-4714.2021v24n2p476.13.

Editora/Editor: Profa. Dra. Marta Regina de Leão D’Agord

Submetido/Submitted: 2.4.2021 / 4.2.2021 Aceito/Accepted: 8.4.2021 / 4.8.2021 
Copyright: (C) 2009 Associação Universitária de Pesquisa em Psicopatologia Fundamental/ University Association for Research in Fundamental Psychopathology. Este é um artigo de livre acesso, que permite uso irrestrito, distribuição e reprodução em qualquer meio, desde que o autor e a fonte sejam citados / This is an open-access article, which permits unrestricted use, distribution, and reproduction in any medium, provided the original authors and sources are credited.

\section{Marcio José de Araujo Costa}

Professor do Programa de Pós-graduação em Psicologia da Universidade Federal do Maranhão - UFMA (São Luís, MA, Br); Psicanalista; Bacharel e Especialista em Filosofia; Psicólogo; Mestre e Doutor em Psicologia Social pela Universidade do Estado do Rio de Janeiro - UERJ (Rio de Janeiro, RJ, Br); Pós-doutorado em Psicologia Clínica pela Pontifícia Universidade Católica de São Paulo - PUC-SP (São Paulo, SP, Br) e em Teoria Psicanalítica pela Universidade Federal do Rio de Janeiro - UFRJ (Rio de Janeiro, $\mathrm{RJ}, \mathrm{Br})$.

Rua Piquiá 3, Edifício Eveline 203 - Bairro São Francisco

65076-470 São Luís, MA, Br

costa.marcio@ufma.br

https://orcid.org/0000-0002-8117-3389

This is an open-access article, which permits unrestricted use, distribution, 